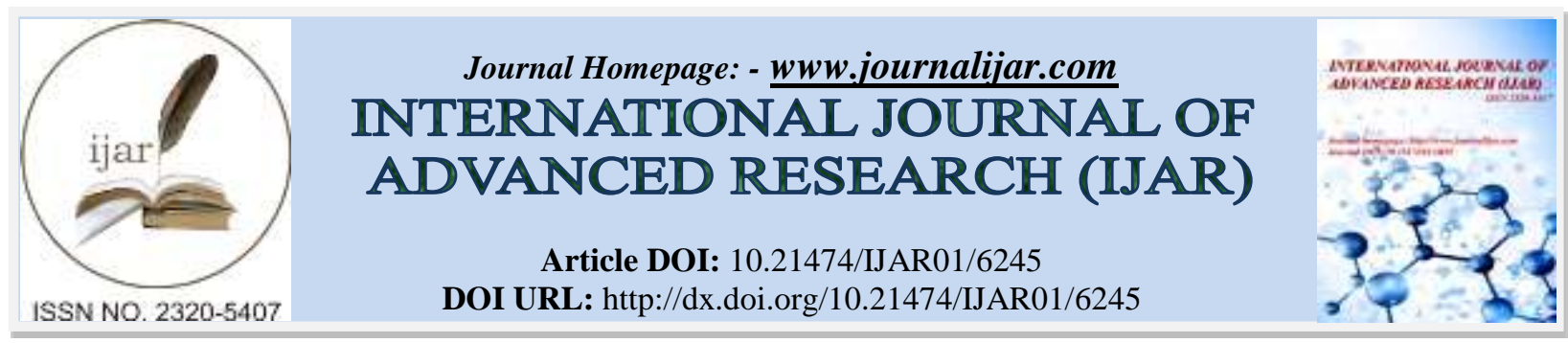

RESEARCH ARTICLE

\title{
METHICILLIN RESISTANT STAPHYLOCOCCUS AUREUS WITH ANTIBIOGRAM IN NASAL CARRIERS AMONG HEALTH CARE WORKERS.
}

Dr. Nazia Begum Mohammed, Dr. P. Ratna Kumari and Dr. R. Lakshmi Kumari. Department of Microbiology, Siddhartha Medical College, Vijayawada - 520008.

\section{Manuscript Info}

\section{Manuscript History}

Received: 07 November 2017

Final Accepted: 09 December 2017

Published: January 2018

Key words:-

Staphylococcus, Methicillin, Carriers, Resistance, Infections.

\begin{abstract}
The present study was carried out in 80 Health Care Workers ( including Doctors, Post graduate students, interns, nursing staff, etc.,.) of government general hospital, Vijayawada to assess the prevalence and antimicrobial susceptibility of Methicillin resistant Staphylococcus aureus among nasal carriers. Carriage of Staphylococcus aureus in the nose appears to play a key role in the epidemiology and pathogenesis of infection. Nasal swabs were collected and screened for Methicillin Resistance Staphylococcus aureus by culturing them on routine basal media. Antibiotic susceptibility was performed by modified KirbyBauer disc diffusion method and methicillin resistance was detected by using Cefoxitine disc diffusion method. Out of 80 samples , 35(43.7\%) were found to be positive for Staphylococcus aureus, followed by Coagulase Negative Staphylococcus, Diptheroids, Micrococci, etc.,.resistance to Methicillin was detected in 17 out of $35(49 \%)$ Staphylococcus aureus. This study showed prevalence of $21 \%$ $M R S A$, which arises to a serious concern about the possibility of transmission of MRSA from the health care workers to the patient. All Staphylococcus aureus isolates, irrespective of their methicillin resistance status were sensitive to Vancomycin \& Linezolid (60\%). The carriage rate of Staphylococcus aureus and MRSA is highest among class IV employees and nurses respectively. This highlights the need of educational activities among Health Care Workers regarding hospital acquired infections and their prevention strategies. Frequent surveillance and effective sterile techniques implementation in these groups will reduce the burden of MRSA in hospitals, leading to decrease of infections.
\end{abstract}

Copy Right, IJAR, 2018,. All rights reserved.

\section{Introduction:-}

Highly virulent strains of Staphylococcus aureus like Methicillin resistance Staphylococcus aureus is responsible for a broad range of nosocomial infections and its resistance to wide range of antimicrobial drugs makes treatment of infections complex. Still awareness is lacking regarding this aspect in various regions of developing countries. Data about nasal carriage of MRSA is limited in our Indian scenario. A health care worker plays a major role in cross contamination of MRSA in developing countries like India. Carriage of S. aureus in the nose appears to play a key role in the epidemiology and pathogenesis of infection. Some group of individuals like Physicians and hospital ward attendants may be nasopharyngeal carriers in a higher percentage of cases (50 and 90\%, respectively) than the 
general population (33\%). The present study aim is to assess the prevalence and antimicrobial susceptibility of Methicillin resistance Staphylococcus aureus in nasal carriers among hospital staff, and survey of infection control practices like hand washing.

\section{Methods:-}

Study was carried out in health care workers ( including doctors, Post graduate students, interns, nursing staff, MNO, FNO, etc.,) of Government General Hospital Vijayawada. Informed consent was taken from all the participants. Nasal swabs from 80 health care workers were collected. Participants who are with immunocompromised conditions like diabetes, HIV, and any usage of recent antimicrobial therapy were excluded. Nasal swabs were collected from anterior nares of nose with pre moistened sterile swab and were transported to microbiology department without any delay and were screened for Staphylococcus aureus by culturing them on nutrient agar (NA) and Mannitol Salt Agar (MSA) by following standard procedures. Antibiotic susceptibility testing of all staphylococcal isolates was performed by modified Kirby Bauer disc diffusion method as recommended by CLSI guidelines. Methicillin resistance was detected by using Cefoxitine disc diffusion test.

\section{Results:-}

Out of 80 samples processed 35 (43.7\%) were found to be positive for Staphylococcus aureus. Other organisms isolated were Coagulase negative Staphylococcus, Diphtheroids, Micrococci, etc. Resistance to Methicillin was detected in 17(49\%) out of 35 Staphylococcus aureus isolates. Nasal carrier rate of MRSA among health care workers was found to be $17(21 \%)$. Among MRSA strains it is seen that more than $60 \%$ isolates were resistant to Penicillin, Azithromycin \& Linezolid. Moderate resistance is seen in Erythromycin \& Amoxicillin- salbactum. Low resistance is seen in Vancomycin, Ciprofloxacin \& Doxycycline. Descriptive statistics were used to summarize the data.

\section{Discussion:-}

Nasal carriage of S.aureus among healthy health care workers attribute to hospital acquired infections like surgical site infections, bacteraemia, etc.,. Our study showed prevalence of $21 \%$ MRSA in anterior nares of health care workers, which is in accordance with findings of Mathai JK et al (21.9\%); and Tsering et al Sikkim (20.9\%) which arises a serious concern about the possibility of transmission of MRSA from the health care workers to the patients. All Staph aureus isolates, irrespective of their methicillin status were, sensitive to Vancomycin and Linezolid (60\%). This study is in relevant with Jawad R et al (59\%). So due to the prevalence of nasal carriers of S.aureus, awareness should be provoked about hygienic hand washing before attending any patients, as hands invariably harbour nasal carriers. Hospital acquired infections commonly originate from health care workers. Although nasal carriage of S. aureus is harmless in healthy individuals, they can become carriers who could pose the risk of spreading infections to the patients. The carriage rate of S. aureus and MRSA is highest among doctors and nurses respectively. When the health care workers were questioned about infection prevention it is seen that most of them were not aware of MRSA and hand hygiene techniques. This highlights the need of educational activities among health workers regarding hospital acquired infections and their prevention strategies. Frequent surveillance and effective lab techniques implemented in these groups, will reduce the burden of MRSA in hospitals which leads to decrease in infections.

\section{Acknowledgement:-}

I am thank full to all the doctors, nursing staff, student and technical staff of Government General Hospital, Siddhartha Medical College, Vijayawada who cooperated us in carrying out this research work.

Table I:- Prevalence of S.aureus and MRSA among healthcare workers

\begin{tabular}{|l|l|l|l|l|}
\hline S no & Health care worer & $\begin{array}{l}\text { No.of samples } \\
\text { taken }\end{array}$ & Staphylococcus aureus & Mrsa \\
\hline 1 & DOCTORS & 7 & 3 & 1 \\
\hline 2 & NURSING STAFF & 56 & 22 & 11 \\
\hline 3 & CLASS IV WORKERS & 8 & 6 & 3 \\
\hline 4 & DIETARY DEPATMENT & 9 & 4 & 2 \\
\hline
\end{tabular}


Table Ii:- Antibiogram

\begin{tabular}{|l|l|l|l|}
\hline Antibiotic & No. Of strains tested & Resistance & Percentage \% \\
\hline Penicillin & $\mathbf{1 2}$ & $\mathbf{9}$ & $\mathbf{7 5 \%}$ \\
\hline Erythromycin & $\mathbf{5}$ & $\mathbf{2}$ & $\mathbf{4 0 \%}$ \\
\hline Doxycyclin & $\mathbf{1 3}$ & $\mathbf{3}$ & $\mathbf{2 3 \%}$ \\
\hline Amoxycillin-salbactum & $\mathbf{1 2}$ & $\mathbf{7}$ & $\mathbf{5 8 \%}$ \\
\hline Vancomycin & 13 & $\mathbf{3}$ & $\mathbf{2 3 \%}$ \\
\hline Linezolid & $\mathbf{5}$ & $\mathbf{3}$ & $\mathbf{6 0 \%}$ \\
\hline Levofloxacin & $\mathbf{2}$ & $\mathbf{2}$ & $\mathbf{1 0 0 \%}$ \\
\hline Ciprofloxacin & $\mathbf{1 7}$ & $\mathbf{2}$ & $\mathbf{1 1 \%}$ \\
\hline Azithromycin & $\mathbf{3}$ & $\mathbf{2}$ & $\mathbf{6 7 \%}$ \\
\hline
\end{tabular}

Figure 1:- Study Group

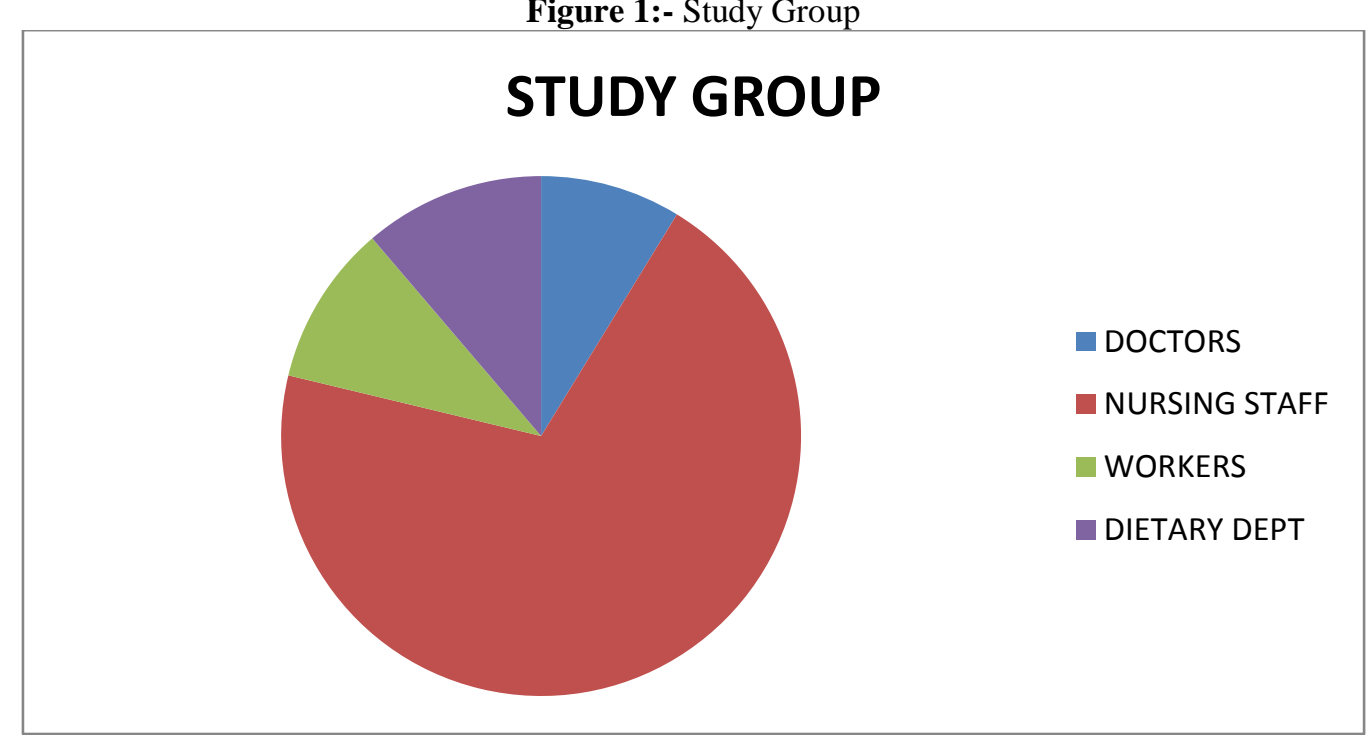

Fig 2:- Nasal Carriers Of Mrsa

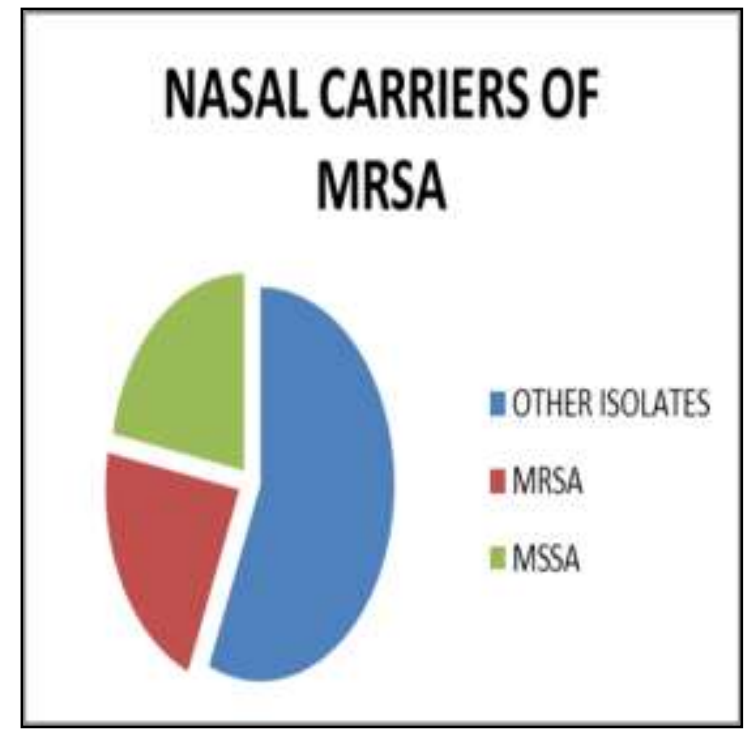


FIG 3:- Distribution of S.aureus \& MRSA among healthcare workers in different fields

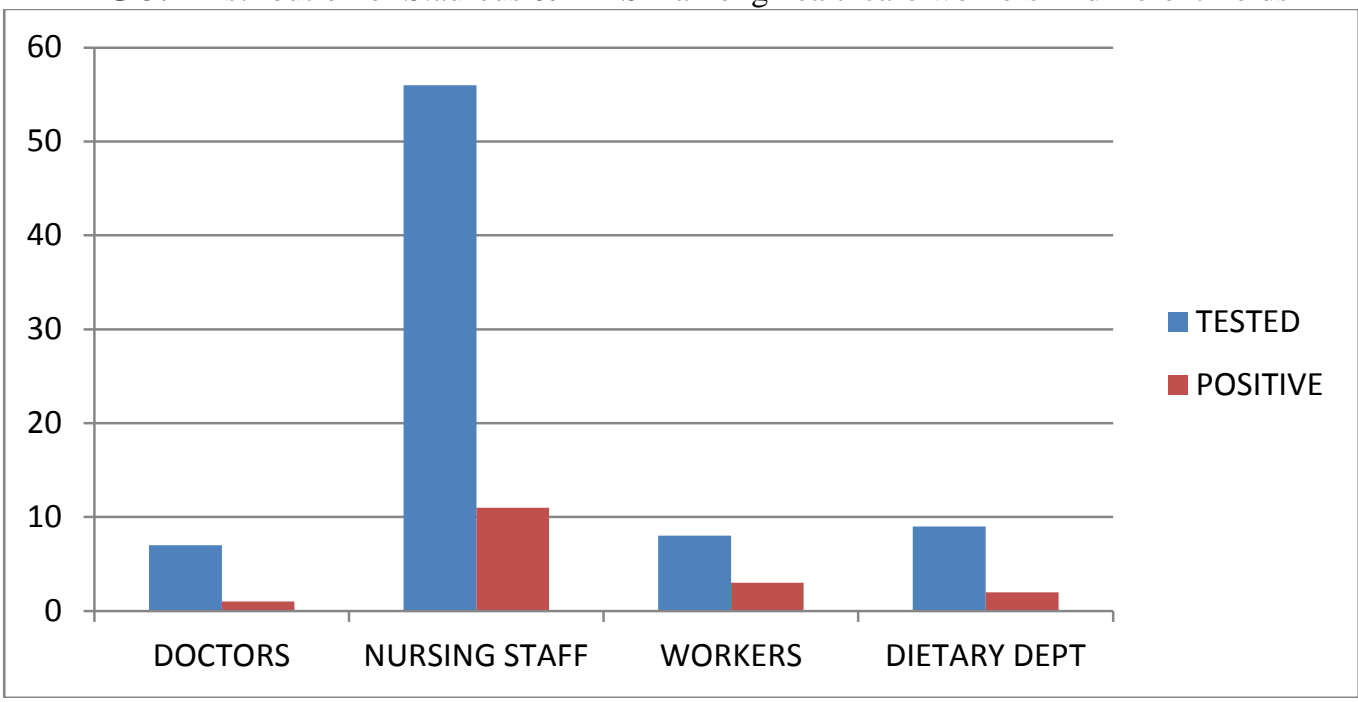

Figure 4:- Antibiotic resistance pattern of MRSA

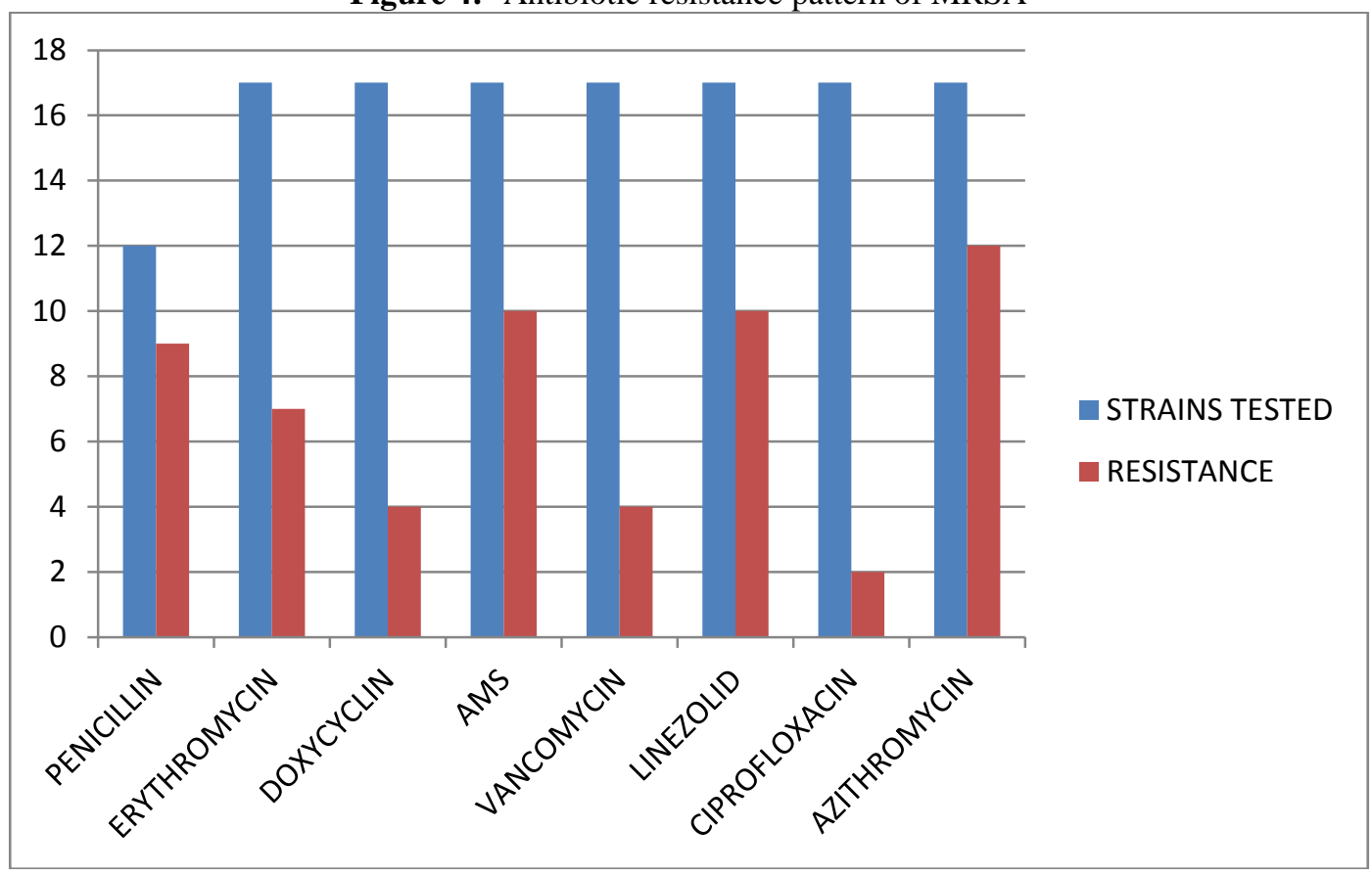




\section{References:-}

1. Mathai JK, Deshmukh DG, Zade AM, Ingole KV, Katkar VJ, Dhobale M Methicillin-Resistant Staphylococcus Aureus : Prevalence And Risk Factors Among Healthcare Workers NJIRM 2013; Vol. 4(4).July - August

2. V Abarna, M Anitha Raj, E Arthi, Bagyalakshmi R, Kavikko Valavan, V Sreenivasalu Reddy Nasal carrier state of METHICILLIN resistant staphylococcus AUREUS in healthy medical students in a tertiary care hospital International Journal of Recent Trends in Science And Technology, ISSN 2277-2812 E-ISSN 2249-8109, Volume 20, Issue 2, 2016

3. Hospital infection control guidelines by ICMR.

4. Clinical and laboratory Standard Institute (2010). Performance Standards for Antimicrobial Susceptibility Testing; Twenty-First Informational Supplement. CLSI document M100-S20 Wayne PA: Clinical and Laboratory Standard Institute.

5. Joshi SC, Diwan V, Tamhankar AJ et al.Qualitative study on perceptions of hand hygiene among hospital staff in a rural teaching hospital in India. J Hosp Infect 2012;80(4): 340-4.

6. Clinical and laboratory Standard Institute (2017). Performance Standards for Antimicrobial Susceptibility Testing; Twenty-First Informational Supplement. CLSI document M100-S20 Wayne PA: Clinical and Laboratory Standard Institute.

7. Koneman E W,Allen SD,Janda W M,Schreckenberger PC ,Winn WC Jr,Gary procop , Gail woods ‘ Koneman's Colour Atlas and textbook of Diagnostic Microbiology, 6th Edition.

8. Shakya B, Shrestha S, Mitra T. Nasal carriage rate of methicillin resistant Staphylococcus aureus among at National Medical College Teaching Hospital, Birgunj, Nepal. Nepal Med Coll J. 2010;12(1):26-9.

9. Cheesbrough M. District laboratory practice in tropical countries, vol. 2. $2^{\text {nd }}$ ed. New York: Cambridge University press; 2006.

10. Farzana K, Rashid Z, Akhtar N, Sattar A, Khan JA, Nasir B. Nasal carriage of staphylococci in health care workers: antimicrobial susceptibility profile. Pak J Pharm Sci. 2008;21(3):290-4.

11. Khalili MB, Sharifi-Yazdi MK, Dargahi H, Sadeghian HA. Nasal colonization rate of Staphylococcus aureus strains among health care service employees of teaching university hospitals in Yazd. Acta Med Iran. 2009;47(4):315-7.

12. Mulqueen J, Cafferty F, Cormican M, Keane JD, Rossney A. Nasal carriage of methicillin-resistant Staphylococcus aureus in GPs in the West of Ireland. Br J Gen Pract. 2007;57(543):811-3.

13. Eveillard M, Martin Y, Hidri N, Boussougant Y, Joly-Guillou ML. Carriage of methicillin-resistant Staphylococcus aureus among hospital employees prevalence, duration, and transmission to households. Infect Control Hosp Epidemiol. 2004;25:114-20.

14. Abudu L, Blair I, Fraise A, Cheng KK. Methicillin-resistant Staphylococcus aureus (MRSA): a communitybased prevalence survey. Epidemiol Infect. 2001;126:351-6.

15. Shibabaw A, Abebe T, Mihret A. Nasal carriage rate of methicillin resistant Staphylococcus aureus among Dessie Referral Hospital Health Care Workers; Dessie, Northeast Ethiopia. Antimicrobial Resist Infect Control. 2013;2:25.

16. Askarian M, Zeinalzadeh A, Japoni A, Alborzi A, Memish ZA. Prevalence of nasal carriage of methicillinresistant Staphylococcus aureus and its antibiotic susceptibility pattern in healthcare workers at Namazi Hospital, Shiraz, Iran. Int J Infect Dis. 2009;13:241-7.

17. S. Mathanraj, S. Sujatha, K. Sivasangeetha, and S. Parija, "Screening for methicillin-resistant Staphylococcus aureus carriers among patients and health care workers of a tertiary care hospital in south India," Indian Journal ofMedicalMicrobiology, vol. 27, no. 1, pp. 62-64, 2009.

18. W.J. Munckhof, G. R. Nimmo, J. M. Schooneveldt et al., "Nasal carriage of Staphylococcus aureus, including communityassociated methicillin-resistant strains, in Queensland adults," Clinical Microbiology and Infection, vol. 15, no. 2, pp. 149-155, 2009.

19. B. O. Olayinka, A. T. Olayinka, A. F. Obajuluwa, J. A. Onaolapo, and P. F. Olurinola, "Absence of mecA gene in methicillinresistant Staphyloccous aureus isolates," African Journal of Infectious Diseases, vol. 3, no. 2, pp. 49-56, 2009.

20. D. K.Warren, R. M.Guth, and C. M. Coopersmith, "Epidemiology of methicillin-resistant Staphylococcus aureus colonization in a surgical intensive care unit," Infection Control and Hospital Epidemiology, vol. 27, pp. 1032-1040, 2006. 